\title{
Experimentation modelling and optimization of electrohydrodynamic inkjet microfabrication approach: a Taguchi regression analysis
}

\author{
AMIT KUMAR BALL ${ }^{1, *}$, RAJU DAS ${ }^{1}$, SHIBENDU SHEKHAR ROY $^{1}$, \\ DAKSHINA RANJAN KISKU ${ }^{1}$ and NARESH CHANDRA MURMU ${ }^{2}$ \\ ${ }^{1}$ National Institute of Technology Durgapur, Durgapur 713209, India \\ ${ }^{2}$ CSIR-Central Mechanical Engineering Research Institute, Durgapur 713209, India \\ e-mail: amit.ball@yahoo.com
}

MS received 3 April 2018; revised 17 April 2019; accepted 24 April 2019; published online 25 June 2019

\begin{abstract}
Electrohydrodynamic (EHD) inkjet is a modern non-contact printing approach, which uses a direct writing technology of functional materials to achieve micro/nanoscale of printing resolution. As an alternative to conventional inkjet technology, the goal of the EHD inkjet printing is to generate uniformly minimized droplets on a substrate. In this study, the effects of applied voltage, standoff height and ink flow rate on droplet diameter formation in EHD inkjet printing process were analysed using Taguchi methodology and regression analysis. Several experiments were carried out using an $\mathrm{L}_{27}\left(3^{13}\right)$ orthogonal array. Based on signal to noise $(S / N)$ ratio and mean response, optimal droplet diameter was achieved. The analysis of variance (ANOVA) was used to find the significance and percentage of contribution of each input parameter along with their interaction on the output droplet diameter. Analysis of the results revealed that the ink flow rate was the dominant factor that affected the droplet diameter mostly. The effect of the applied voltage is significant until regular ejection starts. It helps reduce droplet diameter more than five times compared with its initial droplet diameter in the absence of the electric field. A confirmation test was carried out with a $90 \%$ confidence level to illustrate the effectiveness of the Taguchi optimization method. Both linear and quadratic regression analysis were applied to predict the output droplet diameter. The predicted result from the model and actual test results are very close to each other, justifying the significance of the models.
\end{abstract}

Keywords. Electrohydrodynamic (EHD) inkjet printing; design of experiments (DOE); Taguchi method; analysis of variance (ANOVA).

\section{Introduction}

Electrohydrodynamic (EHD) inkjet printing receives great attention in recent years due to its low-cost production and higher printing resolution with a variety of ink-substrate combinations using a conventional nozzle [1-5]. EHD inkjet technology is a method of obtaining fine jets from the cone-shaped meniscus formed at the tip of the nozzle as a result of a high voltage difference between the nozzle and substrate. It is very difficult to print with the sub-micron level of resolution using conventional ink jet technology, namely thermal or piezoelectric ink jet [1]. These conventional technologies suffer from proper placement of the droplets, the requirement of a huge force to push the ink through a small orifice, nozzle clogging due to ink viscosity, etc. [6]. To achieve higher resolution, one has to design a nozzle with a diameter less than the required

*For correspondence droplet diameter, which is very difficult from a manufacturing point of view [7].

Unlike conventional inkjet technologies that push the fluid through the ink chamber, EHD inkjet is a "pull" processing technology that pulls the ink and results in a higher resolution printing [8]. The prime goal of the EHD inkjet printing system is to maximize the droplet stability (i.e., minimization of droplet deviation from its regular flight path in the presence of high voltage) and to minimize the droplet diameter. It uses a conventional nozzle with a bigger orifice, which makes the EHD system versatile to eject from high-viscosity inks to suspended solid nanoparticle inks and mitigates the nozzle clogging problem. The only "rule of thumb" to avoid nozzle clogging problem is that the size of the ink particle should be 100 times smaller than the inner diameter (ID) of the nozzle [9].

Both the DC and pulse voltage can be used in EHD inkjet technology. Pulse voltage results in a discrete drop generation, which is known as Drop-on-Demand phenomenon and continuous voltage results in a continuous line 
generation. Effect of pulse voltage on the meniscus formation was studied by different groups [3, 10-12]. Cloupeau and Prunet-Foch [13] described the different jetting modes of an EHD system such as dripping mode, cone-jet mode, micro-dripping mode, etc. and also a few variants of cone-jet mode such as pulsed cone jet, multi-cone jet and cone-ramified jet. They also showed that for a specific setting and with a fixed flow rate, different modes of EHD jetting are a function of applied voltage. Choi et al [14] discussed the effects of different jetting parameters in the formation of various jetting modes. Kim et al [15] found the relationship between droplet diameter and pulsed voltage frequency. They used a nozzle with an ID $=200 \mu \mathrm{m}$ and successfully reduced the droplet diameter to about $52 \%$ of the nozzle diameter. Choi et al [10] investigated the effects of various bias voltages and pulse signal on the jetting performance. Han et al [16] used Finite-Element Analysis (FEA) model to predict drop formation and droplet size at the different applied voltages. Xu et al [17] observed that the deposited droplet diameter depends on the deposition frequency and polymer solution supply rate under low-frequency operation. Yu et al [18] defined the minimum flow rate required for steady cone-jet formation. They also investigated the effects of viscosity and elasticity of the ink on the formation of the Taylor cone jet. Park et al [3] used a capillary nozzle of ID $=300 \mathrm{~nm}$ and reduced droplet diameter 20\% (approximately) compared with the nozzle diameter. Lee et al [19] reported that the amplitude of the pulse voltage and its duration determined the charge density accumulated at the tip of the nozzle. Pulse duration was varied from 1 to 500 ms. Micro-dripping mode was observed with the pulse duration of $2.0 \mathrm{~ms}$, and soon it transformed into spindle mode with a pulse duration of $2.1 \mathrm{~ms}$. In another study, Li [11] investigated the effects of pulse voltage and bias voltage on the meniscus formation and transformation of the jetting mode from dripping to pulsating jet and cone-jet mode. He used two different nozzles (the one with ID $=520 \mu \mathrm{m}$ served as a primary nozzle, and ID $=200 \mu \mathrm{m}$ served as a secondary nozzle). The primary nozzle was placed $12 \mathrm{~mm}$ away from the secondary nozzle and served as a ground electrode. Obtained droplet diameter was in a few hundred microns. Wang et al [20] used pulsed EHD inkjet method to generate $45-55 \mu \mathrm{m}$ of droplets and $60 \mu \mathrm{m}$ of continuous tracks of silver. Droplet diameter was reduced by $50 \%$ compared with the nozzle diameter. Different parameter settings were used as seen in the literature, to achieve the minimum droplet diameter as given in table 1. Available literature contains a diverse set of units, associated with every parameter settings used for their study. In order to comprehensively compare their performances, units of the processing parameters are converted to a corresponding uniform indexing. For example, all available flow-rate units (such as $\mathrm{nl} / \mathrm{s}$ or $\mathrm{ml} / \mathrm{h}$ ) are converted to $\mu \mathrm{l} / \mathrm{min}$, and droplet diameters are converted to $\mu \mathrm{m}$.
Park et al [26] paid attention to measure both the cone length and jet length, and hence defined the process to set up standoff height. Laurila et al [27] studied the effects of different parameters on EHD inkjet resolution using a BoxBehnken response surface design (BBD). Another group [28] investigated the effects of pico-flow rates on the droplet size in a stable cone-jet mode using alumina solution at different applied voltages in the range of $5-13 \mathrm{kV}$. In a study [3] it had been shown that the volume of a droplet ejected from the nozzle depends on the applied electric field strength to the ink meniscus. Ejected droplet volume and, therefore, the size are proportional to the pulse width. In the case of a square wave, pulse width depends on the duty cycle and the frequency of the applied pulse [29] as

$$
\text { pulse width }=\frac{\text { duty cycle }}{\text { applied frequency }} .
$$

Understanding the basic physics of the EHD jet formation and identifying the key parameters that influence the outcome of this process are essential to attain high-resolution, stable and reproducible printing. Physics of the EHD inkjet printing system is discussed in detail in [30]. In short, EHD inkjet printing quality is affected by many factors, such as machine operating factors (flow rate, applied potential difference, standoff height) $[11,15,17,19,28,31]$; geometrical factors (ID of the capillary nozzle, nozzle tip structure) [3, 32]; physical properties of ink-substrate (conductivity, viscosity, viscoelasticity, surface tension) $[18,33]$ and some uncontrollable environmental noise factors (humidity, temperature, air pressure).

EHD inkjet printing system was originally proposed to overcome the resolution problem in micro/nanoscale of printing associated with the traditional inkjet system. Uniformly minimized droplets generation in the presence of a noisy environment is the key demand of this technology. Presence of noise factors can be alleviated using some robust optimization techniques. It also helps select the best control factors in a noisy environment. Now a days most of the industrial products and their corresponding processes are very complex, and as a consequence, a simple common sense approach is not enough to get the optimal condition of the quality product. Increased influence of noise factors and decreased accessibility of the control factors reduce the future performances and design activity of the system. Typically $80 \%$ of the engineering designing time is usually spent on firefighting and thus demands a robust engineering framework [34]. A huge number of experiments have to be conducted when the output is influenced by an increased number of input factors. Statistical design of experiment (DOE) is one of the modern techniques that make proper plans of the experiment while reducing these constraints and give valid and objective conclusions. It extracts the maximum statistical information out while reducing the experimental runs. It also reduces product development 
Table 1. Parameter settings to achieve the minimum droplet diameter by different groups.

\begin{tabular}{|c|c|c|c|c|c|}
\hline Author(s) & $\begin{array}{c}\text { Standoff height }(\mathrm{SH} \text { in } \mathrm{mm}) \text {, applied } \\
\text { voltage }(\mathrm{AV} \text { in } \mathrm{kV}) \text {, ink flow rate (FR in } \mu \mathrm{l} / \\
\mathrm{min}) / \mathrm{back} \text { pressure (BP in psi) } \\
\text { combinations }\end{array}$ & Used ink material & $\begin{array}{l}\text { Used nozzle } \\
\text { ID }\left(\mathrm{NZ}_{\mathrm{ID}} \text { in }\right. \\
\quad \mu \mathrm{m})\end{array}$ & $\begin{array}{l}\text { Achieved minimum } \\
\text { droplet diameter }(D \text { in } \\
\mu \mathrm{m})\end{array}$ & Ref. \\
\hline Kim et al & $\mathrm{SH}=1 ; \mathrm{AV}=1 ; \mathrm{FR}=0.18$ & $\begin{array}{l}\text { Ethylene glycol that } \\
\text { contained methylene } \\
\text { blue }(\sim 0.1 \% \text { by mass })\end{array}$ & $\mathrm{NZ}_{I D}=200$ & $D=95-210$ & {$[15]$} \\
\hline Choi et al & $\begin{array}{c}\mathrm{SH}=2 ; \mathrm{AV}=1.4-2 ; \mathrm{FR}=1 \\
\text { Dripping at } 1.4 \mathrm{kV} \text { and micro-dripping } \\
\text { started when } \mathrm{AV} \geq 1.5 \mathrm{kV}\end{array}$ & Commercial silver ink & $\begin{array}{l}\mathrm{NZ}_{I D}=100 \\
\text { Glass } \\
\text { capillary } \\
\text { nozzle }\end{array}$ & $\begin{array}{l}D=550 \pm 16 \text { (at } \\
\text { dripping mode); } D= \\
30 \pm 2 \text { (at micro- } \\
\text { dripping mode) }\end{array}$ & {$[10]$} \\
\hline Park et al & $\begin{aligned} \mathrm{SH}=\sim 0.1 ; & \mathrm{AV}=0.11-0.9 ; \mathrm{FR} \leq \\
& \sim 1.8 \times 10^{-3}\end{aligned}$ & $\begin{array}{l}\text { Polyethyleneglycol } \\
\text { methyl ether solution; } \\
\text { photocurable } \\
\text { polyurethane polymer } \\
\text { and conducting } \\
\text { polymer PEDOT-PSS }\end{array}$ & $\begin{array}{c}\mathrm{NZ}_{I D}= \\
0.3-30 \\
\text { Gold-coated } \\
\text { glass } \\
\text { micro- } \\
\text { capillary } \\
\text { nozzle }\end{array}$ & $\begin{array}{c}D=0.240 \pm 0.050 \text { with } \\
\mathrm{NZ}_{\mathrm{ID}}=0.3 \mu \mathrm{m} \text { and } \\
D=10 \text { um with } \mathrm{NZ}_{\mathrm{ID}}= \\
30 \mu \mathrm{m}\end{array}$ & {$[3]$} \\
\hline $\mathrm{Xu}$ et al & $\begin{array}{l}\mathrm{SH}=1 ; \mathrm{AV}=2.25 ; \mathrm{FR}=1.8 \\
\text { Under low-frequency operation }\end{array}$ & $\begin{array}{c}\text { Polyethylene oxide }(\mathrm{PEO}, \\
\mathrm{MW}=300000 \mathrm{~g} / \mathrm{mol}) \\
\text { diluted with deionized } \\
\text { water }\end{array}$ & $\begin{array}{c}\mathrm{NZ}_{I D}=100 \\
\text { Stainless steel } \\
\text { capillary }\end{array}$ & $D=20$ & {$[17]$} \\
\hline Yu et al & $\begin{array}{c}\mathrm{SH}=25 ; \mathrm{AV}=0-15 ; \mathrm{FR}=\sim 0.833 \text { to } \\
66.66\end{array}$ & $\begin{array}{l}\text { Polyethylene oxide (PEO) } \\
\text { solutions }\end{array}$ & $\mathrm{NZ}_{I D}=180$ & $D=\sim 30$ to 100 & {$[18]$} \\
\hline Lee $e t$ al & $\mathrm{SH}=5 ; \mathrm{AV}=8.7 ; \mathrm{FR}=\sim 3.3$ & Diethylene glycol (DEG) & $\mathrm{NZ}_{I D}=840$ & $\begin{aligned} D= & \sim 135 \text { (in micro- } \\
& \text { dripping mode) }\end{aligned}$ & [19] \\
\hline Xiang et al & $\mathrm{SH}=0.4 ; \mathrm{AV}=1.2 ; \mathrm{FR}=\sim 0.0833$ & Commercial silver ink & $\mathrm{NZ}_{I D}=110$ & $D=45-55$ & [20] \\
\hline Wang et al & $\mathrm{SH}=1 ; \mathrm{AV}=11.2 ; \mathrm{FR}=1.92$ & $\begin{array}{l}\text { Nano-suspension ink } \\
\quad \text { (grade 7631-86-9) }\end{array}$ & $\mathrm{N}_{D}=200$ & $\begin{array}{c}D=60 \pm 8 \\
\text { Stable cone-jet mode }\end{array}$ & {$[21]$} \\
\hline $\begin{array}{l}\text { Poellmann } \\
\quad \text { et al }\end{array}$ & $\mathrm{SH}=0.030 ; \mathrm{AV}=0.25-0.35 ; \mathrm{BP}=1-3$ & ECM proteins & $\begin{array}{c}\mathrm{NZ}_{I D}=5 \\
\text { Coated with a } \\
5 \mathrm{~nm} \text { layer } \\
\text { of } \mathrm{Au} / \mathrm{Pd}\end{array}$ & $D=5$ & [22] \\
\hline Jiang et al & $\begin{array}{l}\mathrm{SH}=3 ; \mathrm{FR}=\sim 0.833 \\
\text { Alternating current with positive voltage of } \\
2.6 \mathrm{kV} \text { and negative voltage of }-1 \mathrm{kV}\end{array}$ & $\begin{array}{l}\text { Polyethylene oxide (PEO, } \\
\qquad \mathrm{Mw}=300 \mathrm{~kg} / \mathrm{mol})\end{array}$ & $\mathrm{NZ}_{I D}=260$ & $\begin{array}{c}D=\sim 205 \text { (with solution } \\
\text { conductivity of } \\
146.5 \mu \mathrm{s} / \mathrm{cm})\end{array}$ & [23] \\
\hline Kim et al & $\begin{array}{c}\mathrm{SH}=0.1 \text {; bias voltage of } 0.650 \mathrm{kV} \text { applied } \\
\text { to the nozzle and pulse voltage of } \\
0.15 \mathrm{kV} \text { applied to the stage }\end{array}$ & $\begin{array}{l}\text { Silver particle ink } \\
\text { dissolved in TGME }\end{array}$ & $\mathrm{NZ}_{I D}=30$ & $D=\sim 15$ & [24] \\
\hline Wu et al & $\mathrm{SH}=0.800 ; \mathrm{AV}=2 ; \mathrm{FR}=2$ & $\begin{array}{c}\text { Pd-loaded } \mathrm{SnO}_{2} \text { nanofibre } \\
\text { ink }\end{array}$ & $\mathrm{NZ}_{I D}=110$ & $D=50-80$ & {$[25]$} \\
\hline
\end{tabular}

time, and increases reliability and performance. One can easily get the overall idea about the system model, reason for changes in the outputs and establish the cause and effect relationship. In recent years, different statistical methods such as factorial design, different regression techniques, analysis of variance (ANOVA), response surface methodology (RSM) and Taguchi methodology are widely used for analysis and optimization of process parameters [35-38].

Aforementioned literature depicted that a detailed statistical analysis was untouched, in order to find the per-cent of influence of the input factors on the performance measures. The objective of this study is to establish the effects of various input parameters on the output droplet diameter obtained from the indigenously developed EHD inkjet printing system. Taguchi methodology had been used to determine the optimal input parameter condition for miniaturization of droplet size. Furthermore, a detail statistical analysis (ANOVA) was performed to find statistically significant process parameters. Results obtained from the Taguchi methodology and regression analysis were validated by conducting some confirmation tests. Remaining part of the paper is organized as follows. Design recipe of the in-house developed experimental set-up, experimental procedure, data collection approach and 
measurement procedure are described in section 2. Results are discussed in section 3 , followed by some concluding remarks in section 4 .

\section{Experimental materials and method}

\subsection{Experimental set-up}

All the experiments were carried out in an indigenously developed EHD inkjet printing system to analyse the effects of various input parameters on the printing performances. Figure 1 depicts the in-house developed experimental setup of the EHD inkjet system. Figure 1(a) shows an overview of the whole system, while figure 1(b) is a zoomed version of the LabVIEW system (interfaced with different hardware components) and figure 1(c) depicts the printed pattern on the substrate. Three prime hardware component of the system, namely the electrical system, pump system and the positioning system, were used to design the whole EHD inkjet printing system. A DC pulsed voltage was generated using a function generator (Make: Tektronix, AFG3022B) and was amplified 1000 times using a highvoltage amplifier (Make: Trek, 10/10B-HS). Therefore a high voltage difference had been created between the conductive nozzle and the substrate. When the ink was

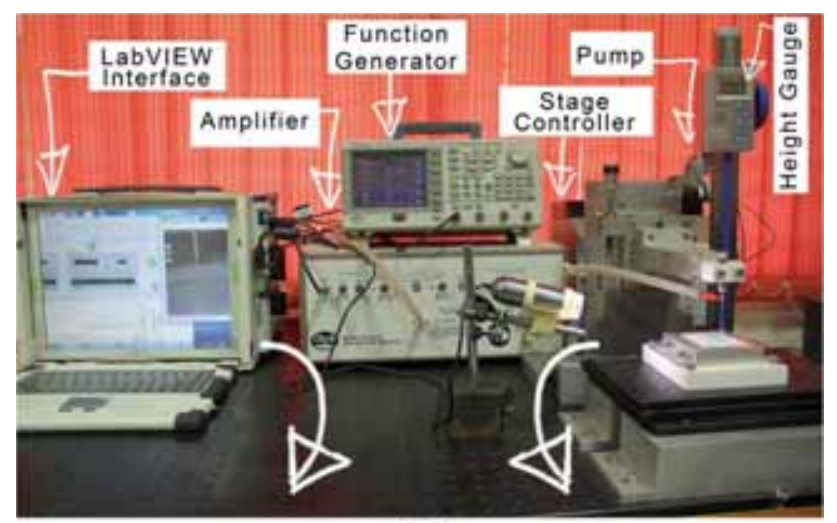

(a)

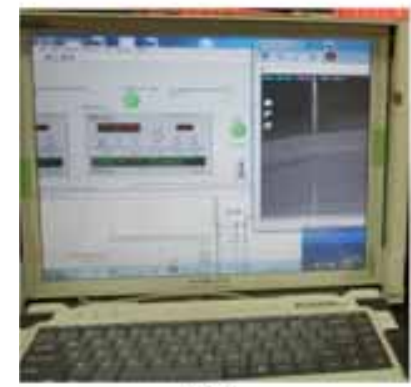

(b)

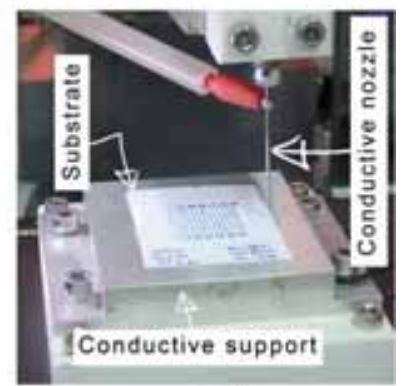

(c)
Figure 1. In-house developed experimental set-up of the EHD inkjet system: (a) overview of the system; (b) zoomed version of the LabVIEW system (interfaced with the different hardware components) and (c) printed pattern on the substrate.
Table 2. PEDOT-PSS (poly(3,4-ethylenedioxythiophene)poly(styrenesulphonate)) ink properties.

\begin{tabular}{lc}
\hline Contains & $1-5 \%$ ethanol, $5-10 \%$ diethylene glycol \\
\hline Concentration & $0.8 \%$ in $\mathrm{H}_{2} \mathrm{O}$ \\
Refractive index & $n 20 / \mathrm{D} 1.340$ \\
$\mathrm{pH}$ & $1.5-2.5$ \\
Viscosity & $7-12 \mathrm{cP}\left(22^{\circ} \mathrm{C}\right)$ \\
Density & $0.985 \mathrm{~g} / \mathrm{mL}$ at $25^{\circ} \mathrm{C}$ \\
\hline
\end{tabular}

pushed through the pump system (Make: KD Scientific, Programmable Legato 210P syringe pump) to the tip of the nozzle, a conical Taylor Cone $[39,40]$ was formed. At the instant when the electrostatic force overcame surface tension, tiny droplets started getting ejected. A commercial polymeric PDOT-PSS solution (poly(3,4-ethylenedioxythiophene)-poly(styrenesulphonate)) purchased from Sigma-Aldrich (St. Louis, MO, U.S.A.) was used as a conductive ink material. Table 2 presents the physical properties of the ink. Specific movement of the $X Y$ scanning stage (Make: ThorLabs, Travel area $=110 \mathrm{~mm} \times 75 \mathrm{~mm}$, MLS203-1) with a Thorlabs BBD series motion controller (Make: ThorLabs, 2-channel bench top 3-phase brushless DC servo controller BBD202) defined the path to be printed. It can be positioned with a resolution of $0.1 \mu \mathrm{m}$ with repeatability of $0.25 \mu \mathrm{m}$, at speed up to $250 \mathrm{~mm} / \mathrm{s}$. Photron's high-speed camera (not shown in the image) with $10000 \mathrm{fps}$ and exposure time of $1.94 \mathrm{~s}$ was used to view the formed Taylor cone, and the flight path of the droplet ejected from the tip of the nozzle. Figure 2 defines droplet ejection from conical Taylor cone using the high-speed camera and a sample output sheet. Droplets were deposited onto a PET (polyethylene terephthalate) substrate using a conductive stainless steel nozzle (Make: Hamilton, Kel-F hub, point style 3, 18 gauge, part number-7750-09) having an ID of $838 \mu \mathrm{m}$ and length of $51 \mathrm{~mm}$. A desktop interface was designed using LabVIEW to integrate different hardware components. A more detailed description of the system can be found in [41].

\subsection{Droplet measurement procedure}

Each PET sheet (size: $4 \times 4 \mathrm{~cm}^{2}$ ) contains several hundred droplets, and it would take a long time to measure each droplet diameter through a microscope. Therefore, to measure the droplet diameter, image processing tools were used in MATLAB R2015b. Deposited PET substrate was scanned at a resolution of 600 ppi. These 8 -bit greyscale images have $2^{8}$ different possible shades of white and black. Droplet colour was darker than the substrate colour. Hence, transferring the image into a binary image file, it was easy to pull out the droplet boundary information data from the scanned sheets. Recommended settings given by Kwon [42] were used here to find the droplet diameter; the 


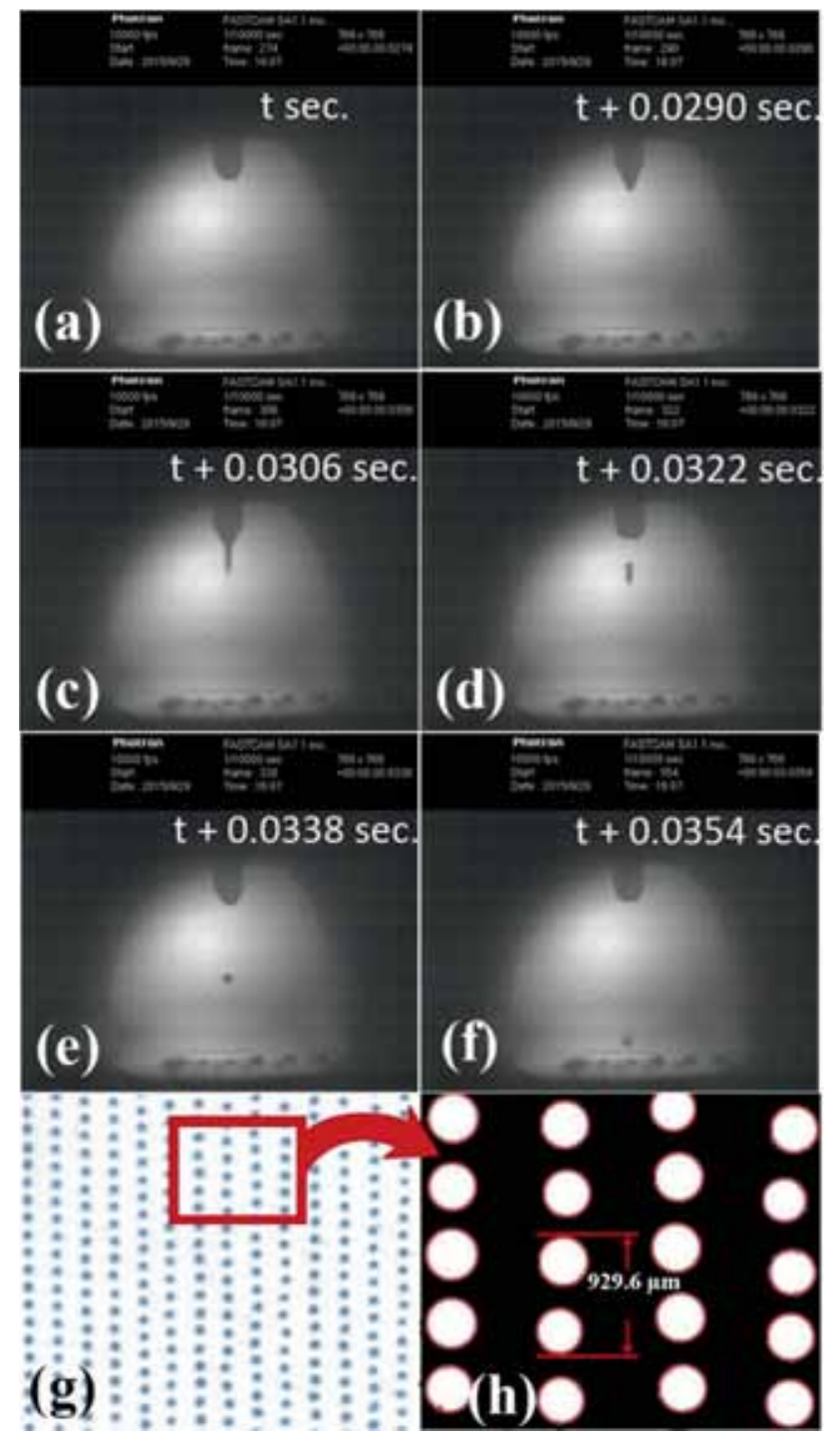

Figure 2. Flights of an ejected droplet captured with a highspeed camera and some sample printed outputs: (a) timing sequence of the ejection initiated at time $t$, (b) Taylor cone image captured after $29 \mathrm{~ms}$, (c) after $30.6 \mathrm{~ms}$, a droplet is about to be ejected, (d) droplet ejected from the tip of the nozzle, (e) ejected droplet follows its regular flight path, (f) after $35.4 \mathrm{~ms}$, droplet is about to be deposited on the PET substrate, (g) deposited output droplets on PET film and (h) processed and zoomed view of the same.

same were validated using an optical microscope (Make: Nikon, Eclipse 50i) and a live viewing CCD Colour Camera (Make: QImaging, High-Speed Real-Time Viewing MicroPublisher 3.3) was attached to the microscope.

\subsection{Taguchi methodology and experimental procedure}

Taguchi methodology is one of the powerful, robust design methodologies that reduce the number of tests run using some orthogonal arrays (OAs) [43]. The main benefits of using Taguchi method are that it decreases the experimental time and cost, minimizes the effect of uncontrollable noise factor and gives significant factor [38, 44-46]. It also helps determine interaction effects if any and finds their significance [47]. The Taguchi methodology is summarized as follows

- define the objective of the study;

- define the output performance parameters;

- select the input process parameters that yield the output performances of the system;

- define the feasible operating range and levels for the selected input process parameters;

- select an effective OA that can accommodate all the selected factors with its associated levels and conduct the experiments according to the $\mathrm{OA}$;

- obtain the results and analyse them;

- conduct the confirmation run and validate the results.

One of the prime key terms in Taguchi methodology is loss function and is defined as the deviation between the experimental value and the desired value, and further, it is converted into signal-noise $(S / N)$ ratio [48], which is the quality characteristic of the output. $S / N$ ratio is a useful, measurable variable instead of considering standard deviation; as the mean decreases, standard deviation decreases too and vice versa. In simple words, $S / N$ ratio determines the level of the desired signal under different noise conditions. Higher $S / N$ ratio indicates higher concentration of useful information than noisy false data [49]. Two major uses of the concept of $S / N$ ratio are to improve the quality by reducing the variability and improve the measurement. $S / N$ ratio characteristics can be divided into categories $[43,50-52]$ as

normal the best

$$
S / N=10 \log \frac{\bar{y}}{S_{y}^{2}}
$$

smaller the better

$$
S / N=-10 \log \left(\frac{1}{n} \sum_{i=1}^{n} y_{i}^{2}\right)
$$

and larger the better

$$
S / N=-10 \log \left(\frac{1}{n} \sum_{i=1}^{n} \frac{1}{y_{i}^{2}}\right)
$$

where $y_{i}^{2}$ is the $i^{\text {th }}$ observation and $n$ is the number of observations of the experiment [51].

The main goal of the EHD inkjet printing process is to increase the printing resolution in a controlled manner with conventional nozzles (having a higher ID). In order to achieve the goal, miniaturization of the droplets is one of the primary objectives of this technology. 
Table 3. Selected factors and their levels.

\begin{tabular}{lccccc}
\hline & & \multicolumn{3}{c}{ Level } & \\
\cline { 3 - 4 } Symbol & Parameter & Low & Medium & High & Unit \\
\hline$A$ & Standoff height & 4.5 & 5.0 & 5.5 & $\mathrm{~mm}$ \\
$B$ & Applied voltage & 7.6 & 8.8 & 10 & $\mathrm{kV}$ \\
$C$ & Flow rate & 10 & 25 & 40 & $\mu \mathrm{l} / \mathrm{min}$ \\
\hline
\end{tabular}

In the study, standoff height $(A)$, applied voltage $(B)$ and ink flow rate $(C)$ were selected as the control factors. The ranges of these control factors were selected after a few trials run. In the absence of high voltage, when the ink was ejected with the help of the gravitational force, the average droplet diameter was $5.099 \mathrm{~mm}$ (using the needle with an ID of $838 \mu \mathrm{m}$ ) with the flow rate of $40 \mu \mathrm{l} / \mathrm{min}$ and standoff height of $4.5 \mathrm{~mm}$. Next, an electrostatic field was applied between the nozzle-substrate (gap) and the force was increased gradually. Operating EHD inkjet ejection started when the applied voltage increased to $7.6 \mathrm{kV}$. The amplifier can generate up to $10 \mathrm{kV}$. Therefore the applied voltage range was selected between 7.6 and $10 \mathrm{kV}$. It is to be mentioned, that in current software settings, it is very hard to adjust the other voltage components such as frequency and the duty cycle of the pulsed voltage through LabVIEW and therefore excluded from this study. During the whole experiment, applied pulsed voltage frequency was set to $16.5 \mathrm{~Hz}$ and the duty cycle was $5.8 \%$. A non-linear relationship among the input-output parameters can be revealed if more than two levels of input factor are analysed [53]. Therefore, each factor was investigated at three levels. The base level amplitude of the pulsed voltage was set to $0 \mathrm{~V}$, and high level was divided into three equally spaced levels between 7.6 and $10 \mathrm{kV}$, i.e., $7.6,8.8$ and $10 \mathrm{kV}$. The distance between the tip of the nozzle and the substrate is called the standoff height. Stable jets were found between the standoff height of 4.5 and $5.5 \mathrm{~mm}$. Similarly, the range of the ink flow rate was finalized after a few trials were run and 10, 25 and $40 \mu \mathrm{l} / \mathrm{min}$ were selected for this experiment. Table 3 shows the input process parameters, their operating range and associated levels.

For the experimental plan, Taguchi recommended using an OA, linear graphs and interaction table, which are customizable using various techniques such as combining columns or collapsing settings [54]. In this study, secondorder interaction terms, viz. $A \times B$ (interaction between standoff height and applied voltage), $A \times C$ (interaction between standoff height and flow rate) and $B \times C$ (interaction between applied voltage and flow rate), were also decided to be investigated and their influences on the droplet diameter formation to be analysed. Since all three variables having 3 levels and three interactions were considered in this study, the total degree of freedom required was $18[=(3 \times 2)+(3 \times 4)]$. Therefore a three-level OA which has at least 18 degrees of freedom was selected. $\mathrm{L}_{27}$ $\left(3^{13}\right)$ OA was the most suitable for this study [20]. It has 27 different combinations of input parameters (26 degrees of freedom) and can accommodate 13 columns at 3 levels each as shown in table 4. A standard linear graph as given in figure 3 was used to assign different control factors and their corresponding interactions to the various columns of the $\mathrm{OA} \mathrm{L}_{27}\left(3^{13}\right)$. To determine optimal droplet diameter and analyse the effects of these input parameters, plan of the experiment was as follows: the first column was assigned to standoff height $(A)$, the second column to the applied voltage $(B)$ and the fifth column to the ink flow rate $(C)$. The third and fourth columns were assigned for the interaction between $A$ and $B$, the sixth and seventh columns to the interaction between $A$ and $C$, and finally to estimate the interaction between $B$ and $C$, eighth and eleventh columns were assigned. A variation in the outcome of a system is due to the influences of control factors and uncontrollable noise factors. A robust system must be immune to uncontrollable noise influences and must reduce the variability of the product/process outcome without removing the cause of variations. Whenever possible, a multiple-replication of the same set of experiment is recommended to determine the $S / N$ ratio, which is considered to be a variance index. A higher value of this index leads to a lower outcome variance around the target value $[45,51,55]$. Therefore three replications were considered for each combination, which resulted in a total of $(27 \times 3) 81$ numbers of experiments. In order to eliminate the biasness, all trials were conducted in a random order. Any additional noise effects were not included in this study, and the effects based on measurement error were considered to be minimal and insignificant. The prime aim of this study is to minimize the droplet diameter. Therefore "smaller the better" quality characteristic was chosen for this experimental work.

\section{Results and discussion}

The mean value of the droplet diameter was obtained after repeating each of the experiments three times while maintaining the same operating conditions. Droplet diameter was measured for each of the input combinations, and the optimal parameter conditions were determined by $S / N$ ratios used in Taguchi methodology. Uniformly placed and minimized droplets are the key demands of the EHD inkjet printing system. For this reason, "smaller the better" quality characteristic was used for the calculation of $S / N$ ratio. Table 5 shows the droplet diameter in three replications, mean of these replications and their $S / N$ ratio value for each experiment combination. Each replication represents the average droplet diameter in an experiment.

Effects of each factor can be determined from the $S / N$ ratio and mean response table, given in table 6 . This table demonstrates the best settings of control factors for 
Table 4. Full factorial design with an orthogonal array of Taguchi $\mathrm{L}_{27}\left(3^{13}\right)$.

\begin{tabular}{|c|c|c|c|c|c|c|c|c|c|c|c|c|c|}
\hline \multirow[b]{3}{*}{ Exp. no. } & \multirow{3}{*}{$\begin{array}{c}A \\
1\end{array}$} & \multirow{3}{*}{$\begin{array}{l}B \\
2\end{array}$} & \multirow{3}{*}{$\begin{array}{c}A \times \\
B \\
3\end{array}$} & \multirow{2}{*}{$\begin{array}{c}A \times \\
B\end{array}$} & \multirow{3}{*}{$\begin{array}{l}C \\
5\end{array}$} & \multirow{3}{*}{$\begin{array}{c}A \times \\
C \\
6\end{array}$} & \multirow{3}{*}{$\begin{array}{c}A \times \\
C \\
7\end{array}$} & \multirow{3}{*}{$\begin{array}{c}B \times \\
C \\
8\end{array}$} & \multicolumn{5}{|c|}{$B \times$} \\
\hline & & & & & & & & & - & - & $C$ & - & - \\
\hline & & & & 4 & & & & & 9 & 10 & 11 & 12 & 13 \\
\hline 1 & 1 & 1 & 1 & 1 & 1 & 1 & 1 & 1 & 1 & 1 & 1 & 1 & 1 \\
\hline 2 & 1 & 1 & 1 & 1 & 2 & 2 & 2 & 2 & 2 & 2 & 2 & 2 & 2 \\
\hline 3 & 1 & 1 & 1 & 1 & 3 & 3 & 3 & 3 & 3 & 3 & 3 & 3 & 3 \\
\hline 4 & 1 & 2 & 2 & 2 & 1 & 1 & 1 & 2 & 2 & 2 & 3 & 3 & 3 \\
\hline 5 & 1 & 2 & 2 & 2 & 2 & 2 & 2 & 3 & 3 & 3 & 1 & 1 & 1 \\
\hline 6 & 1 & 2 & 2 & 2 & 3 & 3 & 3 & 1 & 1 & 1 & 2 & 2 & 2 \\
\hline 7 & 1 & 3 & 3 & 3 & 1 & 1 & 1 & 3 & 3 & 3 & 2 & 2 & 2 \\
\hline 8 & 1 & 3 & 3 & 3 & 2 & 2 & 2 & 1 & 1 & 1 & 3 & 3 & 3 \\
\hline 9 & 1 & 3 & 3 & 3 & 3 & 3 & 3 & 2 & 2 & 2 & 1 & 1 & 1 \\
\hline 10 & 2 & 1 & 2 & 3 & 1 & 2 & 3 & 1 & 2 & 3 & 1 & 2 & 3 \\
\hline 11 & 2 & 1 & 2 & 3 & 2 & 3 & 1 & 2 & 3 & 1 & 2 & 3 & 1 \\
\hline 12 & 2 & 1 & 2 & 3 & 3 & 1 & 2 & 3 & 1 & 2 & 3 & 1 & 2 \\
\hline 13 & 2 & 2 & 3 & 1 & 1 & 2 & 3 & 2 & 3 & 1 & 3 & 1 & 2 \\
\hline 14 & 2 & 2 & 3 & 1 & 2 & 3 & 1 & 3 & 1 & 2 & 1 & 2 & 3 \\
\hline 15 & 2 & 2 & 3 & 1 & 3 & 1 & 2 & 1 & 2 & 3 & 2 & 3 & 1 \\
\hline 16 & 2 & 3 & 1 & 2 & 1 & 2 & 3 & 3 & 1 & 2 & 2 & 3 & 1 \\
\hline 17 & 2 & 3 & 1 & 2 & 2 & 3 & 1 & 1 & 2 & 3 & 3 & 1 & 2 \\
\hline 18 & 2 & 3 & 1 & 2 & 3 & 1 & 2 & 2 & 3 & 1 & 1 & 2 & 3 \\
\hline 19 & 3 & 1 & 3 & 2 & 1 & 3 & 2 & 1 & 3 & 2 & 1 & 3 & 2 \\
\hline 20 & 3 & 1 & 3 & 2 & 2 & 1 & 3 & 2 & 1 & 3 & 2 & 1 & 3 \\
\hline 21 & 3 & 1 & 3 & 2 & 3 & 2 & 1 & 3 & 2 & 1 & 3 & 2 & 1 \\
\hline 22 & 3 & 2 & 1 & 3 & 1 & 3 & 2 & 2 & 1 & 3 & 3 & 2 & 1 \\
\hline 23 & 3 & 2 & 1 & 3 & 2 & 1 & 3 & 3 & 2 & 1 & 1 & 3 & 2 \\
\hline 24 & 3 & 2 & 1 & 3 & 3 & 2 & 1 & 1 & 3 & 2 & 2 & 1 & 3 \\
\hline 25 & 3 & 3 & 2 & 1 & 1 & 3 & 2 & 3 & 2 & 1 & 2 & 1 & 3 \\
\hline 26 & 3 & 3 & 2 & 1 & 2 & 1 & 3 & 1 & 3 & 2 & 3 & 2 & 1 \\
\hline 27 & 3 & 3 & 2 & 1 & 3 & 2 & 1 & 2 & 1 & 3 & 1 & 3 & 2 \\
\hline
\end{tabular}

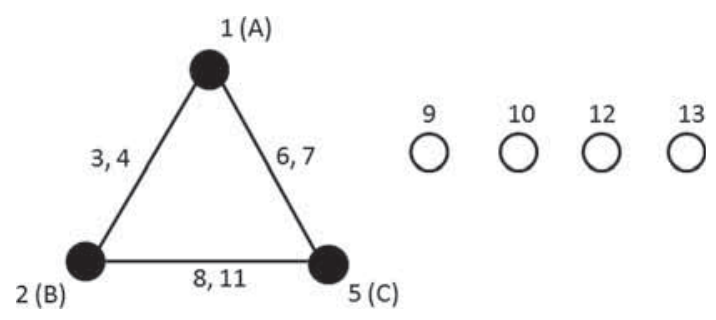

Figure 3. Linear graph of $\mathrm{L}_{27}\left(3^{13}\right)$ orthogonal array.

acquiring optimal droplet diameter. Delta values $(\Delta)$ denote the difference between two successive levels of a factor and reflects the relative influence of the effect. Higher the difference, more powerful the influence.

In order to systematically investigate the effects of standoff height, applied voltage and flow rate on droplet diameter, the main effect plots are obtained by averaging their $S / N$ ratios at different levels and is described in figure 4(a)-(c). It was seen that the $S / N$ ratio values increased with increased values of stand-off height up to a certain limit and then decrease of $S / N$ ratio values was observed with the increased value of stand-off height. The applied voltage is almost parallel to the $x$-axis, which indicates that there are insignificant changes in the $S / N$ ratio values with changes in voltage level. Average $S / N$ ratio value decreased with the increase of flow rate. The mean value of the droplet diameter for different parameter settings is also calculated and is plotted in figure 4(a)-(c) as dotted lines. The maximum value of the $S / N$ ratio reflects better performance. Highest $S / N$ ratio and minimum droplet diameter were observed when the standoff height was set to the second level. Not much influences had been observed for the applied voltage. The flow rate has an increasing effect on average droplet diameter. As the flow rate increases, the droplet diameter also increases by reducing the $S / N$ ratio. The optimum level of the droplet diameter was observed at the $2^{\text {nd }}$ level of the standoff height, $3^{\text {rd }}$ level of the applied voltage and $1^{\text {st }}$ level of the flow rate as given in table 7 . Interaction plots for $S / N$ ratio and average droplet diameter are given in figure 4(d)-(f). If two interaction lines are parallel to each other, it signifies there may not be any interaction effects present between these factors. If the lines have an angle, whether they intersect or not, they must have an interaction effect [51]. In this study, standoff height, applied voltage and flow rate seem to have an interaction 
Table 5. Experimental results and their corresponding $S / N$ ratio values. $\bar{T}$ (Average $S / N$ ratio value) $=-56.07 \mathrm{~dB}$.

\begin{tabular}{|c|c|c|c|c|c|}
\hline \multirow[b]{2}{*}{ Exp. no. } & \multicolumn{3}{|c|}{ Average droplet diameter $(\mu \mathrm{m})$} & \multirow[b]{2}{*}{ Mean of three replications $(\mu \mathrm{m})$} & \multirow{2}{*}{$\begin{array}{l}\text { Signal to noise } \\
\text { ratio }(\mathrm{dB})\end{array}$} \\
\hline & Replication 1 & Replication 2 & Replication 3 & & \\
\hline 1 & 576.87 & 521.37 & 565.66 & 554.63 & -54.89 \\
\hline 2 & 752.57 & 822.00 & 801.33 & 791.97 & -57.98 \\
\hline 3 & 865.93 & 890.00 & 859.75 & 871.90 & -58.81 \\
\hline 4 & 416.33 & 420.00 & 422.67 & 419.67 & -52.46 \\
\hline 5 & 775.97 & 814.80 & 798.83 & 796.53 & -58.03 \\
\hline 6 & 843.10 & 911.13 & 870.12 & 874.78 & -58.84 \\
\hline 7 & 473.70 & 431.60 & 458.65 & 454.65 & -53.16 \\
\hline 8 & 771.07 & 770.00 & 762.53 & 767.87 & -57.71 \\
\hline 9 & 960.00 & 965.40 & 952.40 & 959.27 & -59.64 \\
\hline 10 & 451.83 & 426.80 & 433.37 & 437.33 & -52.82 \\
\hline 11 & 479.00 & 499.60 & 482.70 & 487.10 & -53.75 \\
\hline 12 & 699.00 & 673.00 & 690.38 & 687.46 & -56.75 \\
\hline 13 & 359.03 & 366.25 & 384.65 & 369.98 & -51.37 \\
\hline 14 & 630.00 & 625.00 & 622.65 & 625.88 & -55.93 \\
\hline 15 & 701.00 & 701.00 & 694.69 & 698.90 & -56.89 \\
\hline 16 & 360.00 & 364.73 & 372.17 & 365.63 & -51.26 \\
\hline 17 & 458.60 & 450.00 & 447.93 & 452.18 & -53.11 \\
\hline 18 & 639.63 & 630.00 & 624.82 & 631.48 & -56.01 \\
\hline 19 & 525.00 & 530.45 & 522.92 & 526.12 & -54.42 \\
\hline 20 & 825.45 & 801.10 & 807.48 & 811.34 & -58.18 \\
\hline 21 & 850.00 & 831.00 & 843.64 & 841.55 & -58.50 \\
\hline 22 & 553.73 & 539.93 & 542.81 & 545.49 & -54.74 \\
\hline 23 & 849.57 & 855.23 & 846.27 & 850.36 & -58.59 \\
\hline 24 & 831.85 & 841.33 & 828.00 & 833.73 & -58.42 \\
\hline 25 & 490.00 & 497.90 & 501.05 & 496.32 & -53.92 \\
\hline 26 & 825.00 & 807.00 & 822.31 & 818.10 & -58.26 \\
\hline 27 & 940.00 & 957.15 & 932.18 & 943.11 & -59.49 \\
\hline
\end{tabular}

effect. $A_{2} B_{3}, A_{2} C_{1}$ and $B_{3} C_{1}$ are optimum interaction combinations but to check whether they are significant or not, ANOVA has to be conducted.

In the absence of the electric field, the system can generate droplets if the flow rate is sufficiently high. When the kinetic energy of the liquid is greater than the critical surface energy, droplets are deposited on the substrate [56]. In this inactive mode of the amplifier, the obtained droplet diameter was $5.099 \mathrm{~mm}$ (using the needle with an ID of $838 \mu \mathrm{m})$. In the next step, voltage was applied and gradually increased, which led to increasing electrostatic force. In EHD inkjet printing methodology, high electrostatic field between the nozzle and the substrate forms a conical Taylor-cone. Ink ejection at the apex of the Taylor cone can be explained as a contest between the electrostatic force and surface tension. Considered standoff height should ensure that Taylor cone must be formed and maintained at the nozzle tip within that specified nozzle to substrate distance. Ejection started when the applied voltage potential exceeded a certain critical value. Jetting was observed from the tip of the cone rather than the tip of the nozzle. The jet diameter and electric field strength are inversely proportional [57]. Decreasing standoff height leads to increased pulling force between the nozzle and substrate, which results in a bigger sized droplet. In contrast, if the standoff height is too large, the electrostatic force becomes less impactful. Surface tension force dominates more intensively, which also results in a bigger droplet diameter [58]. Analysis results also support the selection of the second level of the standoff height as an optimal level. After regular ejection started, applied voltage became less impactful, due to the reduced duty cycle of the pulsed voltage, which led to less concentration of the power.

ANOVA was studied to find the relative significance level of the process parameters and quantify their influences on the selected performance characteristic. Table 8 gives the ANOVA results for both the $S / N$ ratio and means. It reflects all the significant and insignificant factors. In statistical analysis, pooling is a common practice of disregarding the less contributing factors. The pooling out factors from the ANOVA table increase the error DOF as well as its contribution but also ensures a conservative estimate and true contributing factors by eliminating insignificant terms $[45,51]$. This can be achieved by a significance test at the desired confidence level.

In this study, a significance test had been carried out by comparing the $F$-ratio of the factors obtained in table 8 with that of the standard $F$-table value with $90 \%$ confidence 
Table 6. $S / N$ ratio and mean response table for droplet diameter.

\begin{tabular}{|c|c|c|c|c|c|c|c|c|c|c|}
\hline \multirow[b]{3}{*}{ Factors } & \multicolumn{6}{|c|}{ Average values of $S / N(\mathrm{~dB})$ ratio and means $(\mu \mathrm{m})$} & \multicolumn{4}{|c|}{$\Delta$ values } \\
\hline & \multicolumn{2}{|c|}{ L1 } & \multicolumn{2}{|c|}{ L2 } & \multicolumn{2}{|c|}{ L3 } & \multicolumn{2}{|c|}{$\Delta 1=\mathrm{L} 2-L 1$} & \multicolumn{2}{|c|}{$\Delta 2=L 3-L 2$} \\
\hline & $S / N$ ratio & Means & $S / N$ ratio & Means & $S / N$ ratio & Means & $S / N$ ratio & Means & $S / N$ ratio & Means \\
\hline$A$ & -56.83 & 721.3 & -54.21 & 528.4 & -57.17 & 740.7 & 2.63 & -192.8 & -2.96 & 212.2 \\
\hline$B$ & -56.23 & 667.7 & -56.14 & 668.4 & -55.84 & 654.3 & 0.09 & 0.7 & 0.30 & -14.1 \\
\hline$C$ & -53.23 & 463.3 & -56.84 & 711.3 & -58.15 & 815.8 & -3.61 & 247.9 & -1.31 & 104.5 \\
\hline$A \times B$ & -56.19 & 670.5 & -55.84 & 648.9 & -56.19 & 671.0 & 0.35 & -21.6 & -0.35 & 22.2 \\
\hline$A \times C$ & -55.83 & 641.1 & -56.22 & 671.7 & -56.16 & 677.7 & -0.39 & 30.6 & 0.06 & 6.0 \\
\hline$B \times C$ & -56.40 & 682.7 & -55.89 & 654.1 & -55.92 & 653.6 & 0.51 & -28.6 & -0.03 & -0.5 \\
\hline
\end{tabular}

Bold values are the optimal level.

level. Higher $F$ ratio defines a higher contribution to the output. $F$-ratios for both the $S / N$ ratio and means suggest removing factor $B$ and interaction $A \times B$ as their $F$-value is less than the required critical $F$-value. $F$-ratio of factor $B$ is 1.11, which is less than the $F(n 1, n 2)=3.113$ at $(1-0.90)=0.1$ significance level, where $n 1=2$ is the DOF of factor $\mathrm{B}$ and $n 2=8$ is the DOF of error term. Similarly, interaction $A \times B$ was also removed from the ANOVA table. DOF of the removed term would contribute in the increase of error DOF and hence would change the error variance as well as the $F$-ratio of the remaining factors. Final pooled ANOVA is given in table 9. It gives a very strong evidence that the standoff height and flow rate have significant effects on the performance measure. Flow rate explains $63.66 \%$ of the total variation and highest contribution in $S / N$ ratio. The second contribution comes from the standoff height with $26.55 \%$. It has been observed that applied voltage does not contribute much within this specified operating range, although it is an important factor to initiate the EHD inkjet ejection. However, the interactions $A \times C$ and $B \times C$ were also insignificant at the $90 \%$ confidence level.

\subsection{Prediction of droplet diameter under optimized condition}

From $S / N$ ratio analysis and mean response characteristics, the optimum level of control factors was obtained. Factor $B$ and the interactions $A \times B$ were excluded from the estimation, as they had a less significant contribution as seen in ANOVA table 8 . Factors $A, C, A \times C$ and $B \times C$ were found to be significant at $90 \%$ confidence level. To estimate the optimum droplet diameter at the optimum condition $A_{2} B_{3} C_{1}$ by considering interaction terms, the following equation can be used [44]:

$$
\eta_{\text {opt }}=\left(\overline{A_{2}}-\bar{T}\right)+\left(\overline{B_{2} C_{1}}-\bar{T}\right)+\bar{T}
$$

where $\overline{A_{2}}$ is the average effect of level 2 of factor $A, \bar{T}$ is the average $S / N$ ratio obtained from the experimental study (table 5) and $\overline{B_{2} C_{1}}$ is the combined average effect of factors $B_{2}$ and $C_{1}$. From ANOVA table 8 , factor $C$ is also significant and gives optimum value at level 1 . However, $C_{1}$ is already included in Eq. (4) and need not be included again. The second pair of interaction $A_{2} C_{1}$ also has been included with its respective factor level and hence need not be considered again for the estimation of the mean at the optimal condition.

$$
\text { Now } \begin{aligned}
\overline{A_{2}} & =-54.21, T=56.07 \text { and } \\
\overline{B_{2} C_{1}} & =(-53.16-51.26-53.92) / 3=-52.78 .
\end{aligned}
$$

Substituting the values in Eq. (4) gives

$$
\eta_{\text {opt }}=-50.92 \mathrm{~dB} \text {. }
$$

Reliability condition is assumed to be $90 \%$; then the confidence interval can be calculated by the following equation $[45,51]$ :

$$
C I=\left[F_{\alpha, 1, f e} V_{e}\left\{\frac{1}{n_{e f f}}+\frac{1}{R}\right\}\right]^{1 / 2}
$$

and

$$
n_{e f f}=\frac{N}{1+T_{\text {dof }}}
$$

where $F_{\alpha, 1, f e}$ is the F-ratio at $90 \%$ confidence level and $\alpha=$ $(1.0-0.9)=0.1, f e=14$ is the degree of freedom for error, $V_{e}$ is the variance of the error term (from pooled ANOVA table 9), $R$ is the number of replications considered for the confirmation experiment and $n_{\text {eff }}$ is the effective number of the replications, $N$ is the total number of results or number of $S / N$ ratios and $T_{d o f}$ is the total DOF associated with the estimate of the mean response. Now by substituting $\quad N=27, T_{\text {dof }}=(2 \times 2)+2=6, F_{(\alpha, 1, f e)}=$ 3.102, $V_{e}=0.46, R=3$ in Eqs. (5) and (6), the values of $n_{\text {eff }}$ and $C$ Ibecome 3.857 and \pm 0.9196 , respectively. Thus, with $90 \%$ confidence level, the estimated optimal $S / N$ ratio of the droplet diameter is $(-50.92 \pm 0.9196) \mathrm{dB}$, i.e. confirmation result should be within -51.84 and $-50.0 \mathrm{~dB}$. 


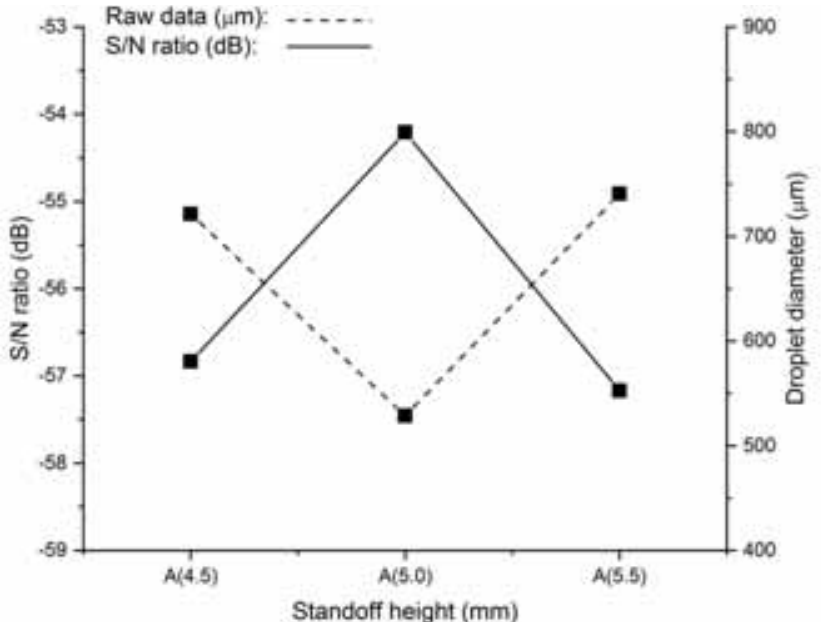

(a)

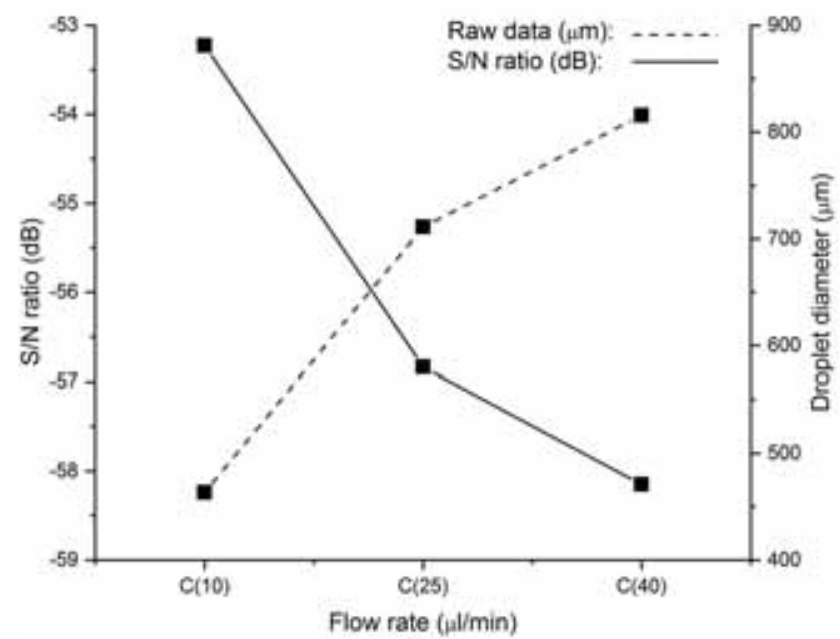

(c)

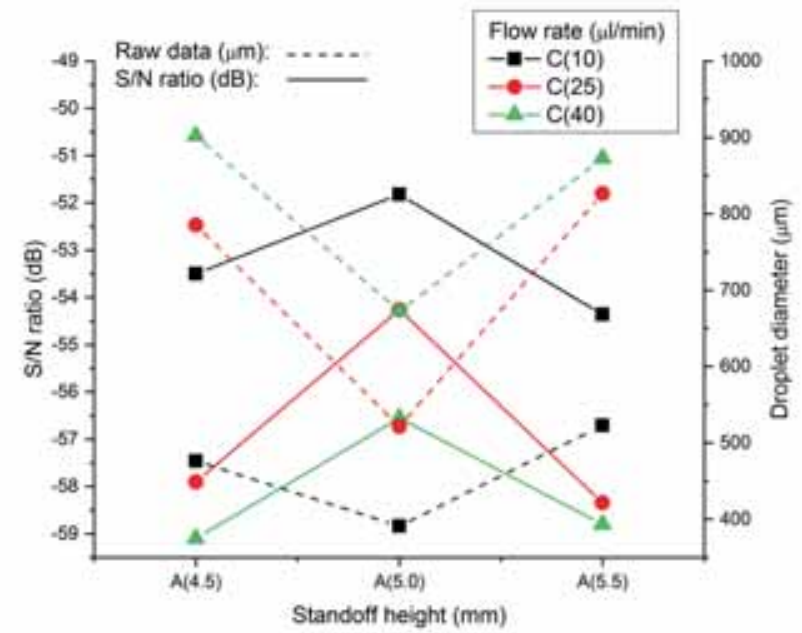

(e)

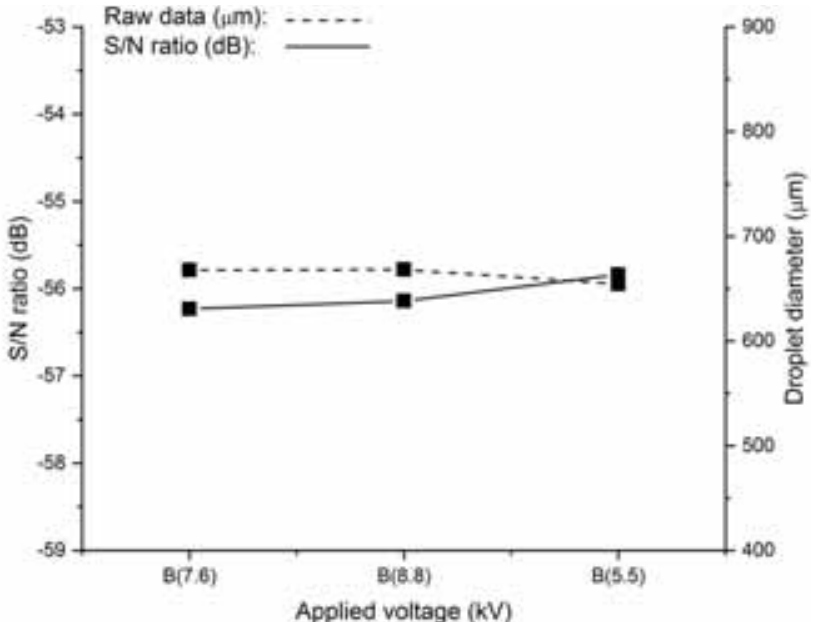

(b)

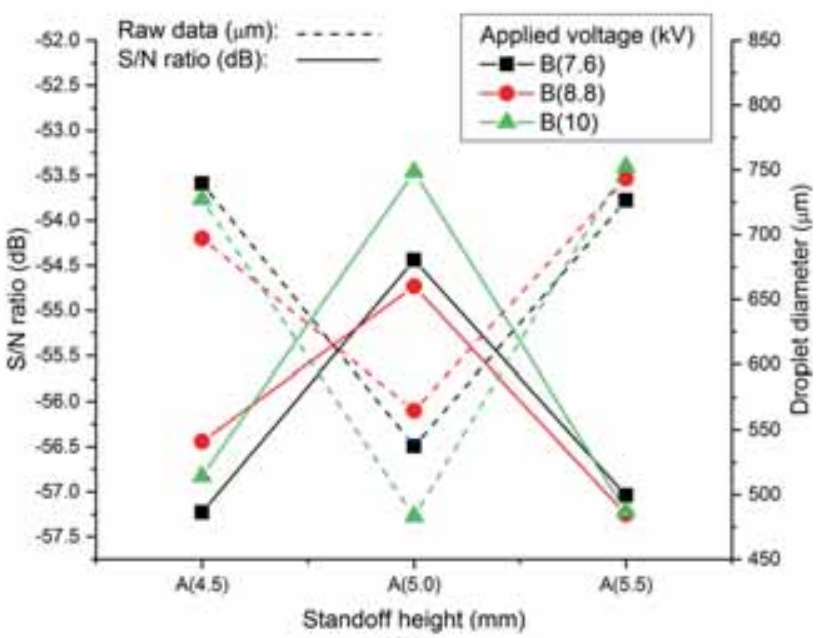

(d)

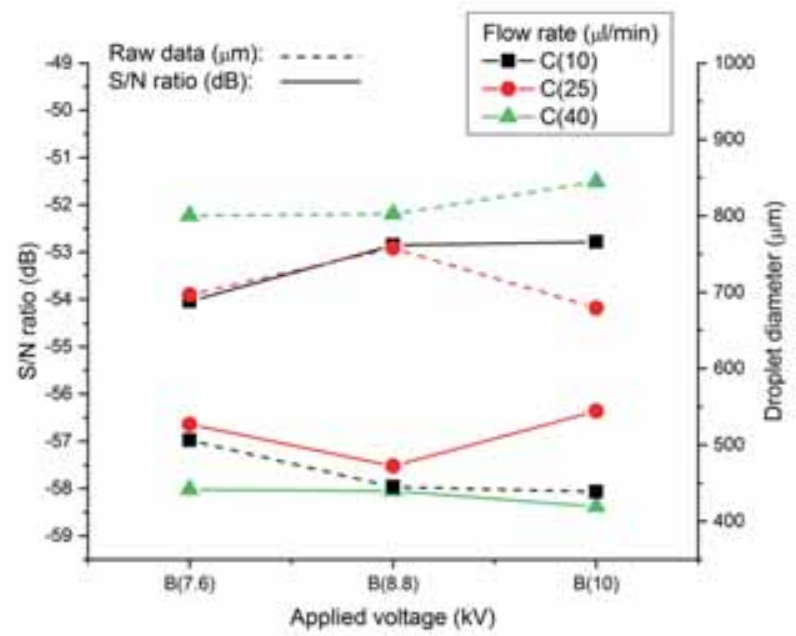

(f)

Figure 4. Effect of process prameters on average droplet diameter and $S / N$ ratio for (a) standoff height, (b) applied voltage and (c) flow rate, and interactions effects for (d) standoff height-applied voltage, (e) standoff height-flow rate and (f) applied voltage-flow rate. 
Table 7. Factors and their corresponding optimum value.

\begin{tabular}{lccc}
\hline $\begin{array}{l}\text { Parameter } \\
\text { code }\end{array}$ & $\begin{array}{c}\text { Parameter } \\
\text { name }\end{array}$ & $\begin{array}{c}\text { Optimum } \\
\text { level }\end{array}$ & $\begin{array}{c}\text { Optimum } \\
\text { value }\end{array}$ \\
\hline$A$ & Standoff height & 2 & $5.0 \mathrm{~mm}$ \\
$B$ & $\begin{array}{c}\text { Applied } \\
\text { voltage }\end{array}$ & 3 & $10 \mathrm{kV}$ \\
$C$ & Flow rate & 1 & $10 \mu \mathrm{l} / \mathrm{min}$ \\
\hline
\end{tabular}

\subsection{Estimation of expected results from $S / N$ ratio to its original units}

Based on the factor effects, the range of the optimum condition must be transferred to its original unit (droplet diameter in $\mu \mathrm{m})$. Estimated average droplet diameter $\left(D_{\text {exp }}\right)$ at optimal condition must lie within the range $[45,51]$

$$
\begin{array}{r}
\sqrt{10^{\frac{50}{10}}}<D_{\exp }<\sqrt{10^{\frac{51.84}{10}}} \\
316.24 \mu \mathrm{m}<D_{\exp }<390.82 \mu \mathrm{m} .
\end{array}
$$

\subsection{Confirmation tests}

With the Taguchi optimization methodology, a confirmation test is required to validate the optimized condition.
Three confirmation runs were conducted at the optimum level based on optimal parameter settings. The average droplet diameter was found to be $D_{\text {exp }}=365.63$. This result was within $90 \%$ confidence interval of predicted optimal droplet diameter value. Therefore confirmation tests depicted the successful optimization.

In optimized condition, achieved droplet diameter was in the range of 360-370 $\mu \mathrm{m}$. Reduced percentage of the droplet diameter $\left(D_{\% \text { reduce }}\right)$ at the optimal condition is as follows:

$$
D_{\%_{\text {reduce }}}=\left(1-\left(\frac{D_{\text {exp }}}{D_{\text {noz }}}\right)\right) \times 100
$$

where $D_{\exp }$ is the droplet diameter obtained at the optimized condition, and $D_{n o z}$ is the used nozzle diameter. On substituting the values of $D_{\exp }$ and $D_{n o z}$ in Eq. (7), droplet diameter reduced up to 57\% (approximately) of the used nozzle diameter. The nozzle with a higher diameter reduces the chance of nozzle clogging. Summary of the optimal settings and the efficiency of the system by means of the miniaturization capabilities are given in table 10 .

Moreover, it is believed that much smaller and uniform features can be achieved by utilizing a smaller nozzle ID to reduce the size of the Taylor cone $[3,15]$, increasing the pulse voltage frequency [19], reducing the ink flow rate [14], switching the jetting modes $[10,28]$ or by manipu-

\begin{tabular}{|c|c|c|c|c|c|c|c|c|c|c|c|c|c|}
\hline \multirow[b]{2}{*}{ Source } & \multirow[b]{2}{*}{ DF } & \multicolumn{2}{|c|}{ SS } & \multicolumn{2}{|c|}{$V$} & \multicolumn{2}{|c|}{$F$-ratio } & \multicolumn{2}{|c|}{$p$-value } & \multicolumn{2}{|c|}{ SS } & \multicolumn{2}{|c|}{ Contribution $(\%)$} \\
\hline & & $\begin{array}{l}S / N \\
\text { ratio }\end{array}$ & Means & $\begin{array}{c}S / N \\
\text { ratio }\end{array}$ & Means & $\begin{array}{c}S / N \\
\text { ratio }\end{array}$ & Means & $\begin{array}{c}S / N \\
\text { ratio }\end{array}$ & Means & $\begin{array}{c}S / N \\
\text { ratio }\end{array}$ & Means & $\begin{array}{l}S / N \\
\text { ratio }\end{array}$ & Means \\
\hline A & 2 & 47.30 & 247802 & 23.65 & 123901 & 68.214 & 81.51 & 0.000 & 0.00 & 46.61 & 244761.9 & 25.895 & 26.55 \\
\hline B & 2 & 0.77 & 1136.4 & 0.38 & 568.2 & 1.110 & 0.37 & 0.376 & 0.70 & 0.08 & 0 & 0.042 & 0 \\
\hline $\mathrm{C}$ & 2 & 117.06 & 589944.8 & 58.53 & 294972.4 & 168.803 & 194.06 & 0.000 & 0.00 & 116.36 & 586904.7 & 64.649 & 63.66 \\
\hline$A \times B$ & 4 & 2.89 & 13187.1 & 0.72 & 3296.8 & 2.085 & 2.17 & 0.175 & 0.16 & 1.50 & 7106.9 & 0.836 & 0.77 \\
\hline$A \times C$ & 4 & 4.52 & 36697 & 1.13 & 9174.2 & 3.258 & 6.04 & 0.073 & 0.02 & 3.13 & 30616.8 & 1.740 & 3.32 \\
\hline$B \times C$ & 4 & 4.68 & 20992.7 & 1.17 & 5248.2 & 3.374 & 3.45 & 0.067 & 0.06 & 3.29 & 14912.5 & 1.829 & 1.62 \\
\hline Error & 8 & 2.77 & 12160.3 & 0.35 & 1520.0 & & & & & 9.01 & 37617.3 & 5.008 & 4.29 \\
\hline Total & 26 & 179.99 & 921920.2 & & & & & & & & & 100.0 & 100.0 \\
\hline
\end{tabular}
lating other processing parameters [7].

Table 8. ANOVA table with $90 \%$ confidence level; tabulated $F$-ratio at $90 \%$ confidence level $F(2,8)=3.11312, F(4,8)=2.80643$.

\begin{tabular}{|c|c|c|c|c|c|c|c|c|c|c|c|c|c|}
\hline \multirow[b]{2}{*}{ Source } & \multirow[b]{2}{*}{ DF } & \multicolumn{2}{|c|}{ SS } & \multicolumn{2}{|c|}{$V$} & \multicolumn{2}{|c|}{$F$-ratio } & \multicolumn{2}{|c|}{$p$-value } & \multicolumn{2}{|c|}{ SS } & \multicolumn{2}{|c|}{ Contribution (\%) } \\
\hline & & $\begin{array}{c}S / N \\
\text { ratio }\end{array}$ & Means & $\begin{array}{c}S / N \\
\text { ratio }\end{array}$ & Means & $\begin{array}{c}S / N \\
\text { ratio }\end{array}$ & Means & $\begin{array}{c}S / N \\
\text { ratio }\end{array}$ & Means & $\begin{array}{c}S / N \\
\text { ratio }\end{array}$ & Means & $\begin{array}{c}S / N \\
\text { ratio }\end{array}$ & Means \\
\hline $\mathrm{A}$ & 2 & 47.30 & 247802 & 23.65 & 123901 & 51.47 & 65.5 & 0.000 & 0.00 & 46.38 & 244018.6 & 25.77 & 26.47 \\
\hline B & (2) & $(0.77)$ & $(1136.4)$ & - & - & Pooled & Pooled & - & - & - & - & - & - \\
\hline $\mathrm{C}$ & 2 & 117.06 & 589944.8 & 58.53 & 294972.4 & 127.38 & 155.93 & 0.000 & 0.00 & 116.14 & 586161.4 & 64.52 & 63.58 \\
\hline$A \times B$ & (4) & (2.89) & (13187.1) & - & - & Pooled & Pooled & - & - & - & - & - & - \\
\hline$A \times C$ & 4 & 4.52 & 36697 & 1.13 & 9174.2 & 2.46 & 4.85 & 0.09 & 0.01 & 2.9 & 29130.2 & 1.49 & 3.16 \\
\hline$B \times C$ & 4 & 4.68 & 20992.7 & 1.17 & 5248.2 & 2.55 & 2.77 & 0.09 & 0.07 & 3.83 & 13425.9 & 1.58 & 1.46 \\
\hline Error & 14 & 6.43 & 26483.8 & 0.46 & 1891.7 & & & & & 10.52 & 49184.1 & 6.64 & 5.33 \\
\hline Total & 26 & 179.99 & 921920.2 & & & & & & & & & 100.000 & 100.00 \\
\hline
\end{tabular}

Table 9. $S / N$-pooled ANOVA. 
Table 10. Summary of the optimal parameter combinations.

\begin{tabular}{lc}
\hline $\begin{array}{l}\text { Standoff height (SH in mm), applied voltage } \\
\text { (AV in } \mathrm{kV})\end{array}$ & \\
$\begin{array}{l}\text { and ink flow rate (FR in } \mu \mathrm{l} / \mathrm{min}) \\
\text { combinations }\end{array}$ & $\mathrm{SH}=5 ; \mathrm{AV}=10 ;$ \\
\hline Used ink material & $\mathrm{PEDOT}-\mathrm{PSS}$ \\
Used nozzle ID (NZ $\mathrm{ND}$ in $\mu \mathrm{m})$ & $\mathrm{NZ}_{I D}=838$ \\
Achieved minimum droplet diameter ( $D$ in & $D=365.63$ \\
$\mu \mathrm{m})$ & $\sim 57$ \\
$\%$ of droplet diameter reduced compared to & \\
$\quad$ the nozzle diameter &
\end{tabular}

\subsection{Regression analysis of droplet diameter}

Linear and non-linear regression methods such as multiple linear regression (MLR), partial least squares regression (PLS), principal component regression (PCR), polynomial partial least squares (PLS) regression, support vector machine regression (SVR/LS-SVM) and artificial neural networks (ANNs) are used for modelling, prediction and analysis of several different systems [59-61]. In this study, regression analysis was used to model input-output and to analyse the relationship between dependent variable, viz. droplet diameter, and independent variables, viz. standoff height $(A)$, applied voltage $(B)$ and ink flow rate $(C)$. To predict the output equation for droplet diameter, both the linear and quadratic regression models were used.
Equation (8) gives the predictive linear regression model for droplet diameter. Value of the coefficient of multiple determination, $R^{2}$, is $60.92 \%$, which is obtained from the linear regression model of droplet diameter:

$$
\begin{aligned}
& D=322+19.4 A-5.6 B+11.75 C \\
& R^{2}=60.92 \%, \quad R^{2}(\operatorname{adj})=55.82 \% .
\end{aligned}
$$

The predictive model for the quadratic regression of the droplet diameter is given in Eq. (9). Since the higher order terms did not improve the $R^{2}$-value, the model was restricted up to the quadratic terms.

$$
\begin{aligned}
D= & 20627-8160 A-34 B+26.6 C+810 A \times A-5.1 \mathrm{~B} \\
& \times \mathrm{B}-0.319 \mathrm{C} \times \mathrm{C}+16.0 A \times B \\
& -2.52 A C+1.55 B \times C \\
R^{2}= & 92.59 \%, \quad R^{2}(\mathrm{adj})=88.66 \% .
\end{aligned}
$$

Linear model and quadratic model residual plot for the average droplet diameter is given in figures 5 and 6, respectively. From the linear regression model, it can be seen that the data are not normal, skewed and not exactly random in nature. There may be several outliers. However, from the quadratic regression model, data seem to be normal and randomly spread.

Prediction ability of both the models was estimated by 6 real experimental test cases by selecting the input variable randomly, keeping their respective limits intact. Figure 7

\section{Residual Plots for AVG}

Normal Probability Plot

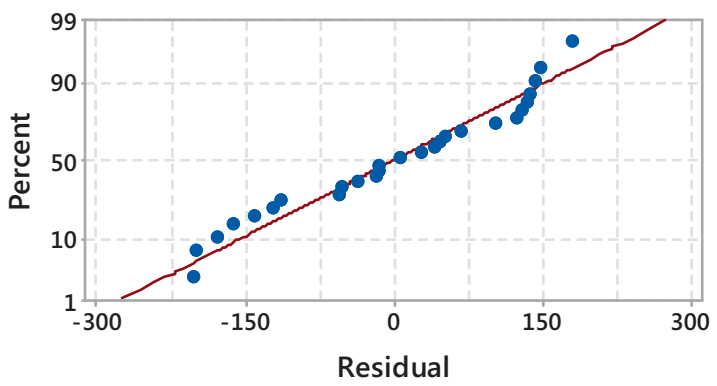

Histogram

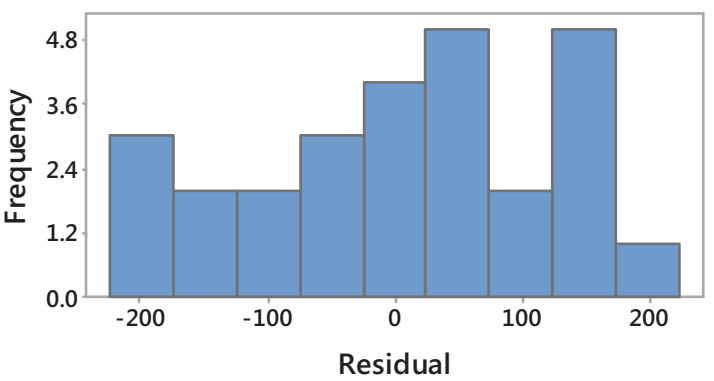

Versus Fits

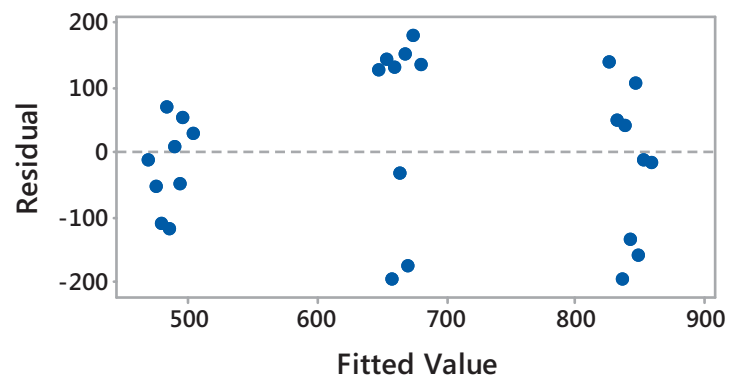

Versus Order

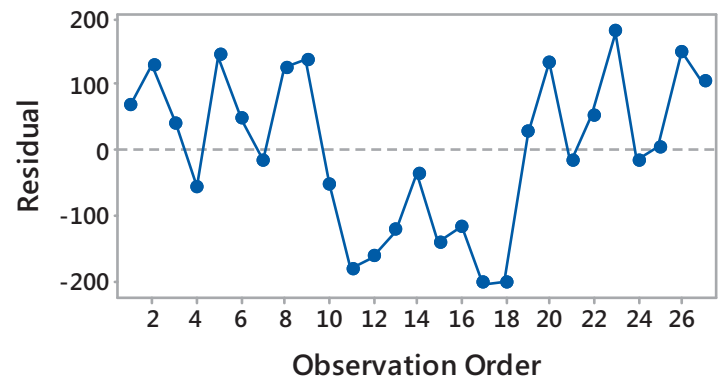

Figure 5. Residual plots for average droplet diameter by the linear regression model. 


\section{Residual Plots for MEAN}
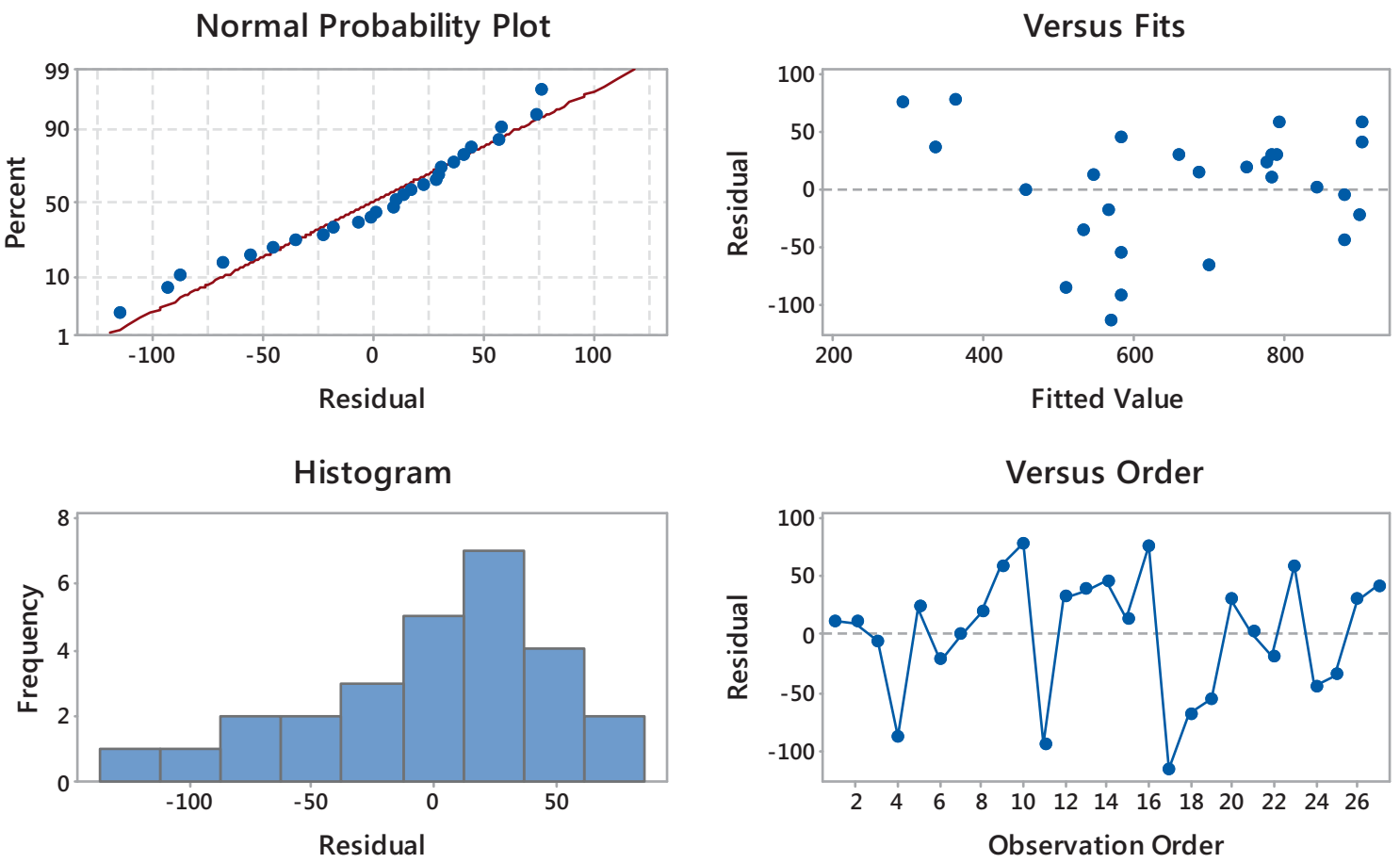

Figure 6. Residual plots for average droplet diameter by the quadratic regression model.

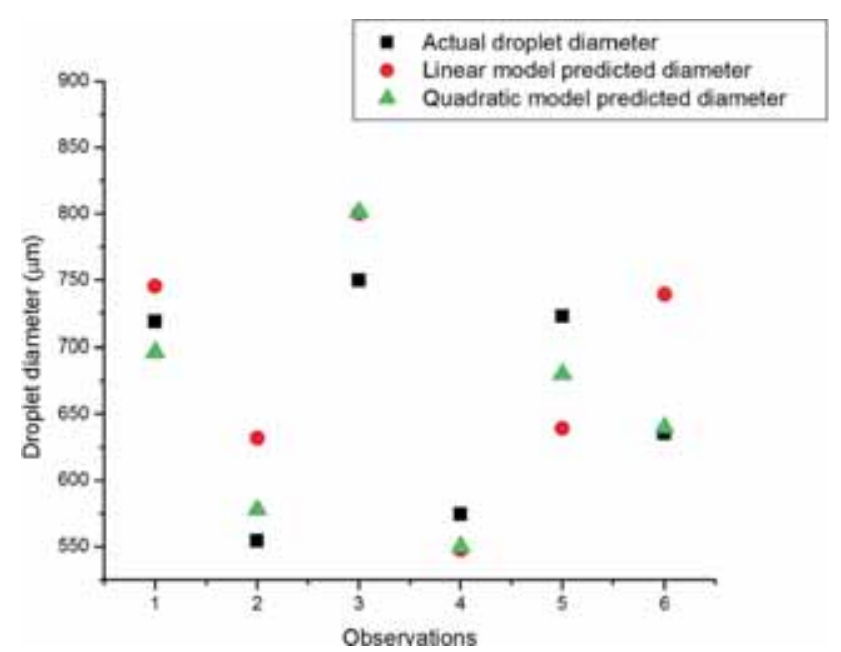

Figure 7. Actual test data, prediction by linear regression model and prediction by the quadratic regression model.

shows the actual result and the predicted values, which were obtained from both the linear regression model and the quadratic regression model as well. The maximum deviation from the actual experimental value for the linear model and the quadratic model was $16 \%$ and $7 \%$, respectively. As seen from figure 7 , there is a very good relationship between the actual data and the predicted data obtained by the quadratic regression relationship. Since the value of the $R^{2}$ is $92.59 \%$, more intensive predictive value can be obtained from this model compared with the linear model. Hence, the result shows that the quadratic regression model gives a better estimation than the linear regression model of droplet diameter.

\section{Conclusion}

The current research work focused on the modelling and optimization of the EHD inkjet printing system. The effects of input process parameters on droplet diameter formation were analysed using Taguchi methodology and regression analysis. Based on the experimental model as well as analysis, the following conclusions are drawn:

- Droplet diameter shows an increasing trend with increase of flow rate and a mixed trend with increase of standoff height. The optimal result can be obtained by selecting the first level of the flow rate and the second level of the standoff height. Applied voltage has less effect on the droplet diameter.

- Based on ANOVA results, the percent contributions of standoff height and flow rate in affecting the variation of droplet diameter are significantly higher at $(90 \%$ confidence level) as compared with applied voltage.

- Interactions applied voltage-flow rate and standoff height-flow rate are also significant at $90 \%$ confidence level, while interactions between standoff height and applied voltage are less significant. 
- Based on "smaller the better quality" characteristic of the $S / N$ ratio, optimal settings of the input process parameter are obtained.

- The predictive average droplet diameter at optimal condition lies within the desired confidence level, and is $57 \%$ smaller than the nozzle diameter.

- Quadratic regression model shows a good relationship with a high correlation coefficient between actual and predicted test results. Predicted values of the droplet diameter are very close to the actual experimental results, which suggest that the quadratic regression model can be used for estimation of the droplet diameter.

\section{Acknowledgements}

This research work was financially sponsored by the Department of Science and Technology (Government of India, Order No DST/TSG/AMT/2015/342, dated 28.07.2016), India. The authors would like to express their gratitude to the Director, NIT Durgapur, and the Director, CSIR-CMERI, Durgapur, for their continuous support and encouragement to carry out the present research work.

\section{References}

[1] Barton K, Mishra S, Alex Shorter K, Alleyne A, Ferreira P and Rogers J 2010 A desktop electrohydrodynamic jet printing system. Mechatronics 20: 611-616. https://doi.org/ 10.1016/j.mechatronics.2010.05.004

[2] Parashkov R, Becker E, Riedl T, Johannes H H and Kowalsky W 2005 Large area electronics using printing methods. Proc. IEEE 93: 1321-1329. https://doi.org/10. 1109/jproc.2005.850304

[3] Park J-U, Hardy M, Kang S J, Barton K, Adair K, Mukhopadhyay D K, Lee C Y, Strano M S, Alleyne A G, Georgiadis J G, Ferreira P M and Rogers J A 2007 Highresolution electrohydrodynamic jet printing. Nat. Mater. 6: 782-789. https://doi.org/10.1038/nmat1974

[4] Lee D Y, Shin Y S, Park S E, Yu T U and Hwang J 2007 Electrohydrodynamic printing of silver nanoparticles by using a focused nanocolloid jet. Appl. Phys. Lett. 90: 1-4. https://doi.org/10.1063/1.2645078

[5] Tan Y, Erick S, Alleyne A G and Cunningham B T 2014 Photonic crystal enhancement of a homogeneous fluorescent assay using submicron fluid channels fabricated by E-jet patterning. J. Biophoton. 7: 266-275. https://doi.org/10.1002/ jbio. 201300158

[6] Szczech J B, Megaridis C M, Gamota D R and Jie Z 2002 Fine-line conductor manufacturing using drop-on demand PZT printing technology. IEEE Trans. Electron. Packag. Manuf. 25: 26-33. https://doi.org/10.1109/tepm.2002. 1000480

[7] Onses M S, Sutanto E, Ferreira P M, Alleyne A G and Rogers J A 2015 Mechanisms, capabilities, and applications of high- resolution electrohydrodynamic jet printing. Small 11: 4237-4266. https://doi.org/10.1002/smll.201500593

[8] Yin Z P, Huang Y A, Bu N B, Wang X M and Xiong Y L 2010 Inkjet printing for flexible electronics: materials, processes and equipments. Chin. Sci. Bull. 55: 3383-3407. https://doi.org/10.1007/s11434-010-3251-y

[9] Cui Z, Han Y, Huang Q, Dong J and Zhu Y 2018 Electrohydrodynamic printing of silver nanowires for flexible and stretchable electronics. Nanoscale 10: 6806-6811. https:// doi.org/10.1039/c7nr09570h

[10] Choi J, Kim Y-J, Lee S, Son S U, Ko H S, Nguyen V D and Byun D 2008 Drop-on-demand printing of conductive ink by electrostatic field induced inkjet head. Appl. Phys. Lett. 93: 193508. https://doi.org/10.1063/1.3020719

[11] Li J L 2006 On the meniscus deformation when the pulsed voltage is applied. J. Electrostat. 64: 44-52. https://doi.org/ 10.1016/j.elstat.2005.04.005

[12] Rahman K, Khan A, Nam N M, Choi K H and Kim D-S 2011 Study of drop-on-demand printing through multi-step pulse voltage. Int. J. Precis. Eng. Manuf. 12: 663-669. https://doi. org/10.1007/s12541-011-0086-8

[13] Cloupeau M and Prunet-Foch B 1994 Electrohydrodynamic spraying functioning modes: a critical review. J. Aerosol. Sci. 25: 1021-1036. https://doi.org/10.1016/0021-8502(94)901 99-6

[14] Choi K, Rahman K, Malik N, Khan A, Kwon K, Doh Y and Kim H 2011 Electrohydrodynamic inkjet - micro pattern fabrication for printed electronics applications. In: Recent Advances in Nanofabrication Techniques and Applications. Rijeka: InTech, pp. 1-22

[15] Kim J, Oh H and Kim S S 2008 Electrohydrodynamic dropon-demand patterning in pulsed cone-jet mode at various frequencies. J. Aerosol. Sci. 39: 819-825. https://doi.org/10. 1016/j.jaerosci.2008.05.001

[16] Han Y, Wei C and Dong J 2014 Super-Resolution Electrohydrodynamic (EHD) 3D Printing of Micro-Structures Using Phase-Change Inks. Manuf. Lett. 2: 96-99

[17] Xu L, Wang X, Lei T, Sun D and Lin L 2011 Electrohydrodynamic deposition of polymeric droplets under lowfrequency pulsation. Langmuir 27: 6541-6548. https://doi. org/10.1021/la201107j

[18] Yu M, Ahn K H and Lee S J 2016 Design optimization of ink in electrohydrodynamic jet printing: Effect of viscoelasticity on the formation of Taylor cone jet. Mater. Des. 89: 109-115. https://doi.org/10.1016/j.matdes.2015.09.141

[19] Lee M W, Kang D K, Kim N Y, Kim H Y, James S C and S S 2012 A study of ejection modes for pulsed-DC electrohydrodynamic inkjet printing. J. Aerosol. Sci. 46: 1-6. https:// doi.org/10.1016/j.jaerosci.2011.11.002

[20] Wang X, Xu L, Zheng G, Cheng W and Sun D 2012 Pulsed electrohydrodynamic printing of conductive silver patterns on demand. Sci. China Technol. Sci. 55: 1603-1607. https:// doi.org/10.1007/s11431-012-4843-4

[21] Wang D Z, Jayasinghe S N and Edirisinghe M J 2005 High resolution print-patterning of a nano-suspension. J. Nanopart. Res. 7: 301-306. https://doi.org/10.1007/s11051-0047772-8

[22] Poellmann M J, Barton K L, Mishra S and Johnson A J W 2011 Patterned hydrogel substrates for cell culture with electrohydrodynamic jet printing. Macromol. Biosci. 11: 1164-1168. https://doi.org/10.1002/mabi.201100004 
[23] Jiang J, Zheng G, Wang X, Zheng J, Liu J, Liu Y, Li W and Guo S 2018 Printing of highly conductive solution by alternating current electrohydrodynamic direct-write. $J$. Phys. Conf. Ser. 986: 012027. https://doi.org/10.1088/17426596/986/1/012027

[24] Kim S, Kang H, Kang K, Lee S, Cho K and Hwang J 2018 Effect of meniscus damping ratio on drop-on-demand electrohydrodynamic jetting. Appl. Sci. 8: 164. https://doi.org/10. 3390/app8020164

[25] Wu H, Yu J, Cao R, Yang Y and Tang Z 2018 Electrohydrodynamic inkjet printing of $\mathrm{Pd}$ loaded $\mathrm{SnO}_{2}$ nanofibers on a CMOS micro hotplate for low power $\mathrm{H}_{2}$ detection. AIP Adv. 8: 055307. https://doi.org/10.1063/1.5029283

[26] Park J, Park J W, Nasrabadi A M and Hwang J 2016 Methodology to set up nozzle-to-substrate gap for high resolution electrohydrodynamic jet printing. Appl. Phys. Lett. 109. https://doi.org/10.1063/1.4963846

[27] Laurila M-M, Khorramdel B, Dastpak A and Mäntysalo M 2017 Statistical analysis of E-jet print parameter effects on Ag-nanoparticle ink droplet size. J. Micromech. Microeng. 27: 095005. https://doi.org/10.1088/1361-6439/aa7a71

[28] Jayasinghe S N and Edirisinghe M J 2005 Electrostatic atomization of a ceramic suspension at pico-flow rates. Appl. Phys. A 80: 399-404. https://doi.org/10.1007/s00339-0032324-0

[29] Mishra S, Barton K L, Alleyne A G, Ferreira P M and Rogers J A 2010 High-speed and drop-on-demand printing with a pulsed electrohydrodynamic jet. J. Micromech. Microeng. 20: 095026. https://doi.org/10.1088/0960-1317/20/9/095026

[30] Korvink J G, Smith P J and Shin D-Y 2012 Inkjet-Based Micromanufacturing. Weinheim, Germany: Wiley-VCH Verlag \& Co

[31] Kwon K-S and Lee D-Y 2013 Investigation of pulse voltage shape effects on electrohydrodynamic jets using a vision measurement technique. J. Micromech. Microeng. 23: 065018. https://doi.org/10.1088/0960-1317/23/6/065018

[32] Youn D-H, Kim S-H, Yang Y-S, Lim S-C, Kim S-J, Ahn S-H, Sim H-S, Ryu S-M, Shin D-W and Yoo J-B 2009 Electrohydrodynamic micropatterning of silver ink using near-field electrohydrodynamic jet printing with tilted-outlet nozzle. Appl. Phys. A 96: 933-938. https://doi.org/10.1007/ s00339-009-5262-7

[33] An S, Lee M W, Kim N Y, Lee C, Al-Deyab S S, James S C and Yoon S S 2014 Effect of viscosity, electrical conductivity, and surface tension on direct-current-pulsed drop-ondemand electrohydrodynamic printing frequency. Appl. Phys. Lett. 105: 214102. https://doi.org/10.1063/1.4902241

[34] Taguchi G, Jugulum R and Taguchi S 2004 Computer-Based Robust Engineering: Essentials for DFSS. Milwoukee, WI: ASQ Quality Press

[35] Panwar N and Chauhan A 2018 Optimizing the effect of reinforcement, particle size and aging on impact strength for Al 6061-red mud composite using Taguchi technique. Sādhanā 43: 101. https://doi.org/10.1007/s12046-018-0870-6

[36] Mohanty S D, Mahapatra S S and Mohanty R C 2019 PCA based hybrid Taguchi philosophy for optimization of multiple responses in EDM. Sädhanā 44: 2. https://doi.org/10. 1007/s12046-018-0982-z

[37] Kalyon A, Günay M and Özyürek D 2018 Application of grey relational analysis based on Taguchi method for optimizing machining parameters in hard turning of high chrome cast iron. Adv. Manuf. 419-429. https://doi.org/10.1007/ s40436-018-0231-z

[38] Asiltürk I and Akkuş H 2011 Determining the effect of cutting parameters on surface roughness in hard turning using the Taguchi method. Meas. J. Int. Meas. Confed. 44: 1697-1704. https://doi.org/10.1016/j.measurement.2011.07. 003

[39] Taylor G 1969 Electrically driven jets. Proc. R. Soc. A Math. Phys. Eng. Sci. 313: 453-475. https://doi.org/10.1098/rspa. 1969.0205

[40] Taylor G 1964 Disintegration of water drops in an electric field. Proc. R. Soc. A Math. Phys. Eng. Sci. 280: 383-397. https://doi.org/10.1098/rspa.1964.0151

[41] Ball A K, Das R, Das D, Roy S S and Murmu N C 2018 Design, development and experimental investigation of E-jet based additive manufacturing process. Mater. Today Proc. 5: 7355-7362. https://doi.org/10.1016/j.matpr.2017.11.405

[42] Kwon K-S and Ready S 2014 Practical Guide to Machine Vision Software: An Introduction with LabVIEW. WileyVCH Verlag GmbH \& Co. KGaA, Weinheim, Germany

[43] Taguchi G, Chowdhury S and Wu Y 2004 Taguchi's Quality Engineering Handbook. Hoboken, NJ, USA: John Wiley \& Sons, Inc.

[44] Ross P J 1996 Taguchi techniques for quality engineering: loss function, orthogonal experiments, parameter and tolerance design. McGraw Hill Professional, New York

[45] Phadke M S 1989 Quality Engineering Using Robust Design. Englewood Cliffs, New Jersey: Prentice Hall

[46] Sanyılmaz M 2006 Design of Experiment and an Application for Taguchi Method in Quality Improvement Activity. Dumlupınar University, Turkey

[47] Taguchi G, Chowdhury S and Yuin W 2005 Taguchi's Quality Engineering Handbook. New Jersey: John Wiley \& Sons

[48] Köksoy O and Zehra Muluk F 2004 Solution to the Taguchi's problem with correlated responses. Gazi Univ. J. Sci. 17: 59-70

[49] Park S H 1996 Robust Design and Analysis for Quality Engineering. London, UK: Chapman and Hall

[50] Taguchi G 1993 Taguchi on Robust Technology Development, 1st ed. Three Park Avenue, New York, NY: ASME

[51] Roy R K 2010 A Primer on the Taguchi Method, 2nd ed. Society of Manufacturing Engineers, Dearborn, Michigan

[52] Shetty R, Pai R B, Rao S S and Nayak R 2009 Taguchi's technique in machining of metal-matrix composites. J. Braz. Soc. Mech. Sci. Eng. 31: 12-20. https://doi.org/10.1590/ S1678-58782009000100003

[53] Byrne D M and Taguchi G 1987 The Taguchi approach to parameter design. Qual. Prog. 20: 19-26

[54] Tsui K L 1992 An overview of Taguchi method and newly developed statistical methods for robust design. IIE Trans. 24: 44-57. https://doi.org/10.1080/07408179208964244

[55] Chowdhury S and Taguchi S 2016 Robust optimization: world's best practices for developing winning vehicles. Wiley, Chichester, UK

[56] Lindblad N R and Schneider J M 1965 Production of uniform-sized liquid droplets. J. Sci. Instrum. 42: 635-638. https://doi.org/10.1088/0950-7671/42/8/338

[57] Choi H K, Park J-U, Park O O, Ferreira P M, Georgiadis J G and Rogers J A 2008 Scaling laws for jet pulsations associated with high-resolution electrohydrodynamic printing. 
Appl. Phys. Lett. 92: 123109. https://doi.org/10.1063/1. 2903700

[58] Wei C and Dong J 2013 Direct fabrication of high-resolution three-dimensional polymeric scaffolds using electrohydrodynamic hot jet plotting. J. Micromech. Microeng. 23: 025017. https://doi.org/10.1088/0960-1317/23/2/025017

[59] Balabin R M and Lomakina E I 2009 Neural network approach to quantum-chemistry data: accurate prediction of density functional theory energies. J. Chem. Phys. 131: 074104. https://doi.org/10.1063/1.3206326
[60] Balabin R M, Lomakina E I and Safieva R Z 2011 Neural network (ANN) approach to biodiesel analysis: analysis of biodiesel density, kinematic viscosity, methanol and water contents using near infrared (NIR) spectroscopy. Fuel 90: 2007-2015. https://doi.org/10.1016/j.fuel.2010.11.038

[61] Balabin R M and Lomakina E I 2011 Support vector machine regression (SVR/LS-SVM) - an alternative to neural networks (ANN) for analytical chemistry? Comparison of nonlinear methods on near infrared (NIR) spectroscopy data. Analyst 136: 1703. https://doi.org/10.1039/c0an00387e 